\title{
ORIGAMI COMO RECURSO DIDÁTICO PARA O ENSINO DE CIÊNCIAS
}

\section{ORIGAMI AS EDUCATIONAL RESOURCE FOR THE TEACHING OF SCIENCES}

\author{
João Paulo Cunha de Menezes \\ Universidade de Brasília/NECBio/jpaulo_bio@hotmail.com
}

\begin{abstract}
Resumo
O trabalho expõe uma abordagem diferenciada no Ensino de Ciências, apresentando resultados de diferentes intervenções didáticas utilizando a arte do origami, permeando reflexões sobre o processo de construção e de aplicação experimental, como contribuição nas práticas pedagógicas na formação inicial de professores. A aplicação do trabalho foi desenvolvida com alunos do curso de Licenciatura em Ciências Biológicas da Universidade de Brasília, na disciplina de Didática das Ciências Naturais. A atividade desenvolvida demonstrou que trabalhar com origami no Ensino de Ciências pode ser considerada uma boa ferramenta de ensino, haja vista que estimula a participação dos alunos podendo despertar criatividade, contribuindo para a construção do conhecimento de forma prática e se mostrando como um ótimo material didático.
\end{abstract}

Palavras-chave: Práticas Pedagógicas; Origami; Ensino de Ciências

\section{Abstract}

The work presents a differentiated approach in Science Teaching, presenting results of different didactic interventions using the art of origami, permeating reflections on the process of construction and experimental application, as a contribution in the pedagogical practices in the initial teacher training. The application of the work was developed with students of the Licentiate course in Biological Sciences of the University of Brasília, in the discipline of Didactics of Natural Sciences. The activity developed showed that working with origami in Science Teaching can be considered a good teaching tool, since it stimulates the participation of the students and can awaken creativity, contributing to the construction of knowledge in a practical way and showing itself as a great didactic material.

Keywords: Pedagogical practices; Origami; Science teaching.. 


\section{Introdução}

Discussões sobre os problemas relativos a melhorias no ensino no Brasil, principalmente dos alunos de ensino básico, há muito tempo vem sendo alvo de relevantes estudos e questionamentos. A melhoria do ensino tem sido destacada como uma preocupação de autoridades governamentais e acadêmicas (AGUIAR, 2017).

No centro dessas preocupações destacamos como problema o Ensino de Ciências que, de uma maneira geral, sempre foi muito discutido (FOUREZ, 2003; TREAGUST; TSUI, 2016). Em decorrência da baixa carga horária disponibilizada para o Ensino de Ciências, os professores se deparam com dificuldades de ensinar, sendo um grande problema enfrentado pelos docentes da rede pública, aliado à falta de estrutura, isso pode acabar desmotivando o professor a desenvolver práticas pedagógicas diferenciadas, e com isso suas aulas acabam se tornando modelos tradicionais (FOUREZ, 2003). Brasil (2006) afirma que é comum que as aulas expositivas sejam o único meio utilizado, deixando ao mesmo tempo a ideia de que correspondem uma técnica pedagógica desinteressante e cansativa. Neste modelo de racionalidade técnica, também considerada como modelo tradicional de ensino, não há interação entre professores e estudantes, seguindo a utilização única dos livros didáticos como a única fonte de conhecimento (SETÚVAL; BEJARANO, 2009).

Os sistemas escolares na Educação Básica concentram-se mais na aquisição de competências. A ênfase não é mais sobre o conhecimento adquirido pelos alunos, mas sobre como os estudantes são capazes de trabalhar e utilizar essas informações. Assim, para que o Ensino de Ciências contribua com a formação do aluno, no qual tem por objetivo prepara-lo para o desenvolvimento de suas habilidades no percurso de sua vida à conquista da cidadania, é essencial que o professor tome consciência de suas próprias concepções sobre o ensino, como também sobre os processos de aprendizagem (SETÚVAL; BEJARANO, 2009). Segundo Sarmieri e Fustina (2004) conforme citado por Justina e Ferla (2006), professores em formação inicial e continuada têm apontado como necessidades formativas a proposição de recursos didáticos que visem facilitar o processo de ensino e aprendizagem.

Vários métodos de ensino são apresentados, tais como: o uso do lúdico, tecnologias, filmes, modelos tridimensionais, entre outros, cada um prometendo uma revolução na forma de ensinar, ou auxiliando no processo de ensino/aprendizagem. No que tange a proposição de materiais didáticos que facilitam os processos de ensinoaprendizagem, os mesmos constituem recursos atraentes, a exemplo do uso da arte do origami (WANG-IVERSO et al., 2016).

Acredita-se que o origami seja criação japonesa. Apesar de o papel ter sido desenvolvido na China, os origamis mais antigos encontrados datam do século VI d.C., mesmo período em que o papel chegou ao Japão, trazido pelos monges budistas. Ademais, a própria palavra "origami" deriva de duas palavras japonesas, expressão Ori significa dobrar e Kami significa papel. Ori e Kami formam assim a palavra origami. $\mathrm{O}$ objetivo desta técnica designa precisamente a arte de criar figuras diversas utilizando-se dobras geométricas e padrões de vincos num único pedaço de papel, sem cortá-los ou colá-los (FREITAS, 2013). 
Hoje, em diferentes partes do mundo, a arte do origami é utilizada como uma ferramenta educacional, não sendo apenas destinada para a criação de figuras, é uma arte que está ajudando a aprendizagem significativa de diferentes áreas, mesmo nas ciências. O uso desta arte envolve o abandono dos métodos tradicionais e desperta curiosidade nos estudantes, proporcionando o desenvolvimento pessoal, social e profissional. O uso do origami foi observado como uma ferramenta benéfica no Ensino de Ciências em diversas partes do mundo, em uma ampla faixa etária de aprendizado (BOAKES, 2009; GOLAN, 2011, WINCKLER et al., 2011). Embora o origami seja recomendado por diferentes autores como uma ferramenta de instrução benéfica, pesquisas sobre o uso de origami na formação inicial de professores para o Ensino de Ciências ainda é limitado (BOAKES, 2009). Além disso, pesquisas envolvendo o uso de origami estão concentradas principalmente em alunos de escolas primárias e secundárias (CAKMAK, 2009) e no ensino de matemática (RANCAN, 2011).

No Brasil, o uso do origami por parte dos professores ainda é considerado recente, e quando usam, não costumam empregar como uma ferramenta educacional para o ensino e aprendizagem. No que tange ao ensino de ciências, alguns autores sinalizam os benefícios desta arte como ferramenta de aprendizado. Apesar de que o origami não seja uma técnica que esteja explicitamente inscrita nos Parâmetros Curriculares Nacionais (PCN) do Ensino Fundamental (BRASIL, 1998), a utilização do origami no Ensino de Ciências dispões de um leque de possibilidades de formas diferenciadas de trabalhar conceitos básicos e aprofundados. A construção do próprio material didático e sua análise detalhada ajuda o aluno a melhorar o interesse pelas aulas de ciências como também permite maior interação entre professor-aluno. Em adição, as manipulações criativas como essas promovem a habilidade de pensar de forma clara e coerente em termos de raciocínio espacial, o que não tem preço para o processo conceitual. Nesta nova estrutura, os exercícios com origami ajudam a desenvolver um melhor senso de percepção espacial (MEGAHED, 2017).

O uso do origami no processo de ensino e aprendizagem tem sido considerado uma ferramenta inovadora que hospeda inteligências múltiplas (espacial, interpessoal, cenestésica, visual e auditiva) (HOWARD, 1993). Gardner Howard define em seu livro "Inteligências Múltiplas: A teoria na prática" a inteligência como "a capacidade de resolver um problema e criar produtos que têm valor cultural" (HOWARD, 1993, p. 21). O autor observa a importância que tem a arte do origami em estudantes, uma vez que os estudantes ampliam suas habilidades para a elaboração de figuras e ao mesmo tempo seguindo orientações verbais que ajudam a melhorar sua atenção. Em adição, por meio das dobras e manipulação de papel, a construção do origami aumenta a coordenação do estudante, que por sua vez, desenvolve atividades cerebrais (MEGAHED, 2017).

As figuras criadas beneficiam os estudantes a desenvolver habilidades motoras finas, melhorando assim sua autoestima e concentração. Neste contexto, melhora o processo de ensino-aprendizagem como a interação dinâmica entre professor-aluno, porque cria um ambiente de confiança e diversão. Sobre a importância do Origami, Garcia-Gutierrez (1991) afirmam: 
"O origami, além da grande satisfação que você tem quando você terminar de dobrar qualquer forma, oferece a possibilidade de desenvolver talento, criatividade, habilidade, paciência, sabedoria e inúmeros ensinamentos de ir para praticar esta arte." (GARCIA-GUTIERREZ, 1991, p. 10)".

Para Piaget (1995) a formação lúdica, pode ajudar o aluno a assimilar e processar informações e experiências aprendidas. O autor coloca que é importante trabalhar com as variedades de aprendizagem, tanto para a prática quanto para a teoria. Piaget menciona que "quando o sujeito interage com o objeto de conhecimento" (TÉLLEZ et al., 2007, p. 2), os estudantes têm uma conexão direta com seu material de estudo, tendendo uma melhor compreensão com seu aprendizado. Ao construir figuras com o papel, os alunos têm uma ligação direta entre seu cérebro, olhos e mãos, o que estimula os estudantes no desenvolvimento cognitivo e psicológico, uma vez que tem um aprendizado divertido, criativo e motivado ao ser o criador e autor de suas próprias esculturas de papel.

Vygotsky indica que, quando "é feito na interação social" (TÉLLEZ et al, 2007. p. 8), a relação entre os estudantes possibilita a melhora no aprendizado entre os alunos, melhorando a relação entre eles e os seus conhecimentos. A criação de origamis, seguindo instruções verbais e não verbais, melhora as relações pessoais, criatividade e autoestima dos alunos, tornando um aprendizado cooperativo, prático e motivador.

A arte do origami é uma das poucas técnicas trabalhadas como alunos que permite praticar a ligação entre a mente, mãos e olhos, ou seja, a capacidade de criar objetos guiado pelo cérebro sob a intervenção da visão. Entre os benefícios visados pelo uso do origami pode destacar: exercício psicomotor dos estudantes, coordenação, desenvolve a sua criatividade e originalidade, e fornecer aos professores uma ferramenta de apoio ao expor vários temas e assuntos. Nesse contexto, o origami deve ser encorajado entre os professores para que sejam utilizados no ambiente escolar, em aulas de ciências à luz das vantagens cognitivas desenvolvidas. Através dessas atividades, os alunos podem superar o pensamento e se envolver com seus projetos em um nível físico em um ambiente colaborativo (MEGAHED, 2017). Como indicado pelo autor, a arte do origami por ser considerado um bom recurso de ensino em sala de aula, pois mostrou que motiva os alunos na assimilação do conhecimento de forma criativa, divertida, como também ajudam o desenvolvimento de habilidade de audição e motoras.

Portanto, considerando a contribuição válidas do uso do origami em sala de aula este trabalho investiga o efeito dessas atividades sobre diferentes habilidades, permeando reflexões sobre o processo de construção e de aplicação experimental como contribuição nas práticas pedagógicas na formação inicial de professores, para a construção do conhecimento.

\section{Experimento didático}

O trabalho foi elaborado e desenvolvido com a ideia de apresentar uma nova perspectiva para instrumentalização do Ensino de Ciências com uso da arte do origami. A aplicação do trabalho foi desenvolvida com alunos do curso de Licenciatura em Ciências Biológicas da Universidade de Brasília, na disciplina de Didática das Ciências Naturais. 
Para a execução da proposta, foi aplicado um roteiro de atividade disponibilizando fragmentos teóricos de trabalhos sobre o uso de Origami no ensino encontrados na literatura, visando a abertura de uma discussão sobre o tema. Em seguida, foram formados trios de modo a permitir a construção do material com diferentes conteúdos, obedecendo as seguintes etapas: I) construção estética do origami, II) contribuição do origami e do lúdico no processo de compreensão de um tema do conteúdo de ciências e se III) a expressão apresentação feita pelos alunos sobre o conteúdo científico os auxiliou na compreensão do mesmo.

A primeira etapa consistiu em uma breve introdução sobre a arte do origami, explicando sobre sua utilização no mundo e uma roda de conversa no qual foi possível coletar oralmente os conhecimentos dos alunos sobre origami. A segunda etapa consistiu em argumentar aos alunos sobre as possíveis utilização do origami como uma dimensão lúdica com alguns questionamentos sobre o conteúdo científico. A terceira e última etapa foi caracterizada pela apresentação e aplicação dos origamis de forma experimental, tendo a participação de todos os alunos. Concomitantemente houve discussão sobre os origamis apresentados de modo a permitir diferentes pontos de vistas e sugestões como contribuição a sua melhoria. No final de todas as etapas foi aplicado um questionário aos discentes contendo questões sobre os pontos positivos e negativos do uso de origami, além de sugestões de melhorias, pontos de vista sobre a possibilidade da execução prática dos origamis de modo a indicar as contribuições nas práticas pedagógicas dos professores no Ensino de Ciências para a construção do conhecimento no processo de ensino aprendizagem.

\section{Resultados e Discussão}

Em um primeiro momento foi feito uma roda de discussão para a introdução do conteúdo e levantamento/contextualização oral do conhecimento prévio dos discentes. A partir deste momento, começaram a ser trabalhados diferentes temas com os alunos. Ao longo dessa discussão foi sempre dado enfoque aos conteúdos abordados no terceiro e quarto ciclo do Ensino Fundamental (6 ao $9^{\circ}$ ano), mostrando as possibilidades da incorporação da técnica de origami nos conceitos trabalhados em sala de aula. Foram produzidas, ao final da atividade, oito intervenções didáticas utilizando diferentes figuras com uso do origami (Figura 1). 

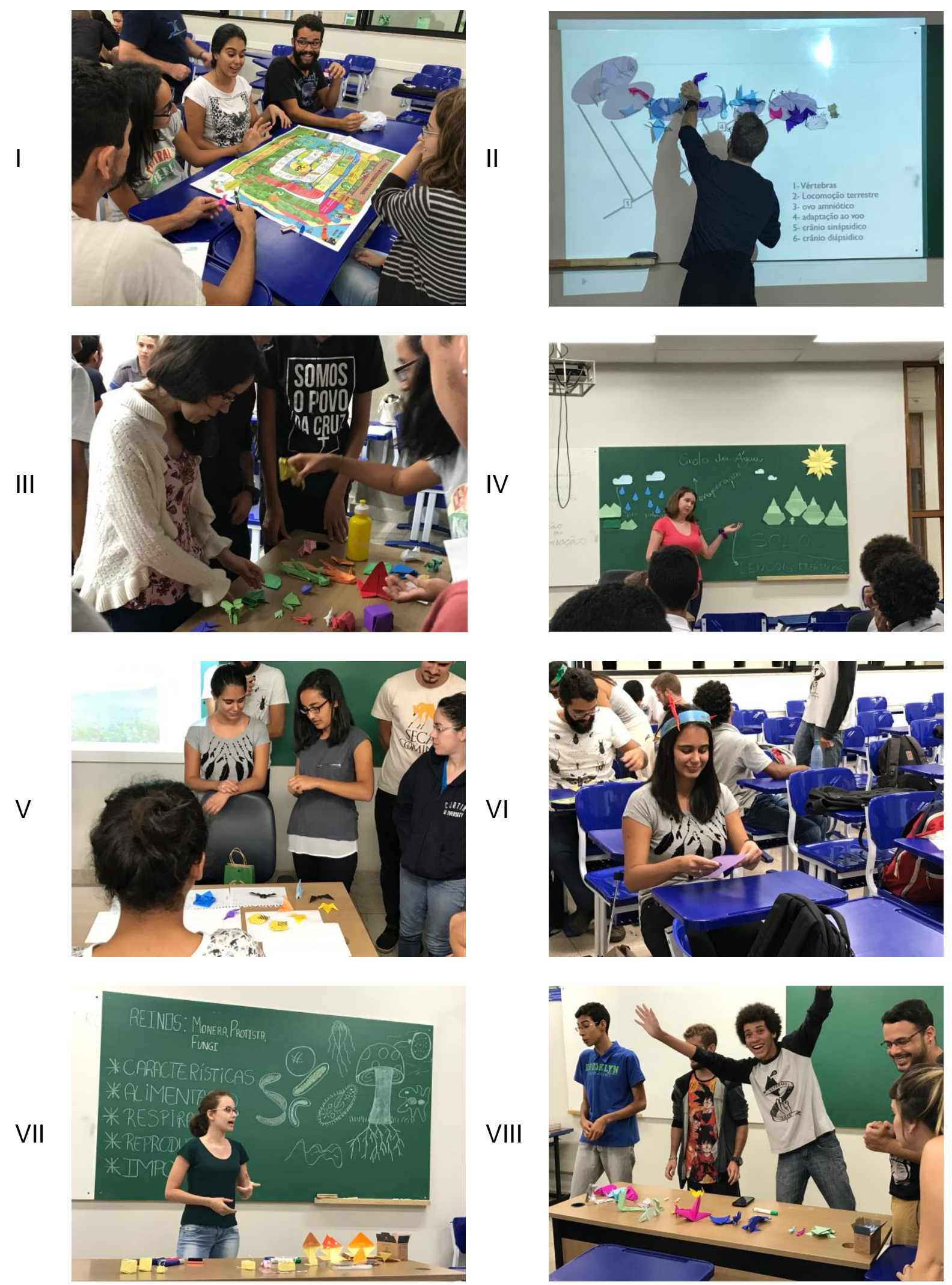

Figura 1. Diferentes intervenções didáticas no Ensino de Ciências: I) Diferentes ambientes em ecossistemas brasileiros; II) Diversidade dos Seres Vivos; III) Cadeias alimentares e outras relações biológicas; IV) O ciclo da água; V) Polinização; VI) Os seres vivo. 
Ao longo das diferentes aplicações e explicações, os alunos mostraram interesse e fizeram diversas perguntas sobre a implementação do origami de forma a instrumentalizar - Ensino de Ciências, aspeto válido para o processo ensino-aprendizado. Pelas expressões dos alunos e pela atenção durante as explicações, pode-se observar que o origami despertou o interesse da turma, trazendo recursos para desenvolver a compreensão sobre temas abstratos. A construção de modelos de origami incentivou o desenvolvimento da criatividade por parte dos futuros professores a partir de experiências com cores, formas e texturas. Ressalta-se a importância de planejamento por parte dos professores para que eles possam fazer novas e diferentes atividades que estimulem os alunos a desenvolverem seu aprendizado e compreensão da melhor maneira.

Segundo Corralee e Sierra (2002) "os instrumentos que, por uma parte ajudam os formadores com sua tarefa de ensinar, por outro, facilita os estudantes a alcançar os objetivos de aprendizagem" (CORRALES; SIERRA, 2002, p. 19). Como fundamentado pelas autoras, um recurso pedagógico é quando facilita a compreensão e assimilação do conhecimento pelos alunos, sendo uma ferramenta eficaz no trabalho educativo dos docentes. A arte do origami é um recurso dinâmico que está distante das aulas expositivas tradicionais, propiciando aos alunos habilidades artísticas que permitem adquirir um conhecimento mais prático, motivador e interessante.

Durante o processo de construção das figuras, algumas questões foram trazidas pelos alunos, devendo as mesmas ser consideradas como instrumentos importantes para a discussão em torno de sua utilização no Ensino de Ciências. Dentre essas, faz jus as que são indicativos de reflexões sobre a importância do trabalho pedagógico, tais como: Por que trabalhar as relações entre os seres vivos, ou outros conceitos por meio do uso de origami? Como argumento a esta indagação, a atividade prática utilizando o origami permite ao estudante aprender de maneira dinâmica, de modo a visualizar diferentes processos, melhorando a fixação dos conteúdos, facilitando o aprendizado, favorecendo seu desenvolvimento cognitivo. $\mathrm{O}$ uso de materiais alternativos pode ser considerado um recurso eficiente que estimula 0 aprendizado em aulas práticas teóricas tornando 0 processo de ensino mais interessante aos estudantes. Neste contexto, incorporar a prática do uso do origami em aulas de ciências pode encorajar o aprendizado entre os alunos.

Nos argumentos trazidos pelos alunos, é evidente que aspectos de visualização para a explicação de diferentes processos nos conteúdos seja um forte indicativo de que o origami consiste em uma boa ferramenta para provocar a socialização de um determinado assunto. Segundo Setúval e Bejarano (2009):

"Em verdade, o modelo didático no que tange ao aspecto visual como forma de explicação de um determinado processo, e, consequentemente, favorecimento ao desenvolvimento cognitivo, tem a sua importância pela correspondência com os modelos mentais. (SETÚVAL; BEJARANO, 2009, p. 7)."

Segundo Axt e Moreira (1991), as Universidades no Brasil deveriam dar maior importância à formação de professores para que materiais didáticos venham a ser produzidos e utilizados, de forma efetivas nas escolas. Enfatiza-se ainda, que o presente 
trabalho constitui um processo de aprendizagem, especialmente no que se refere à parte de metodologia.

Quando indagados sobre o uso do origami no ensino de ciências, as respostas dos alunos apontam para eficiência desta ferramenta. A primeira pergunta apresentava aos estudantes foi se, "Durante as apresentações de diferentes modalidades didáticas com uso do origami houve algum desinteresse". Verificou que 100\% ( $n=40)$ dos alunos responderam que não sentiram desinteresse durante o processo de aprendizagem. Neste contexto, pode-se também considerar a citação de Karling (1991) que afirma.

"... o ensino é procurar os interesses, gostos, necessidades e problemas dos alunos; Escolher conteúdos, técnicas e estratégias; Fornecer materiais adequados e criar ambiente favorável para o estudo." (Karling, 1991, p.23).

Esta afirmação sublinha a necessidade de consolidar os materiais de pesquisa para o Ensino de Ciências. Para esses alunos, materiais e recursos recreativos desempenham um papel importante na construção do conhecimento.

Seguindo essa afirmação, houve também unanimidade dos alunos quanto ao fato de terem gostado das aulas, $87,5 \%(n=35)$ disseram que houve um maior aprendizado do conteúdo com o uso do origami. Os $12,5 \%(n=5)$ não opinaram em relação ao processo de aprendizado. Esse cenário sugere que provavelmente existe um potencial lúdico do uso do origami no ensino de ciências.

Um outro ponto que foi questionado com os alunos foi se houve uma evolução na criatividade na forma de abordar diferentes temas. Na mesma forma que anteriormente $87,5 \%(n=35)$ dos alunos consideraram que houve evolução na criatividade na construção das aulas. Os $12,5 \%(n=5)$ restantes não opinaram. A criatividade pode ser definida pelo grau de satisfação que o aluno obtém de suas criações mais do que por quanto os resultados se aproximam das diretrizes estabelecidas por outras pessoas (MARQUES, 2016).

Por fim, os alunos foram questionados se o fato de aprenderem conteúdo de ciências por meio do origami foi interessante. Dentre os participantes, a maioria dos alunos responderam que as abordagens no Ensino de Ciências com uso do origami foram extremamente interessantes e envolventes, apenas um aluno respondeu discordar totalmente. Esses resultados foram apoiados pelo trabalho de Boakes (2009), cujo estudo indicou que os alunos desenvolvem visões positivas sobre o uso do origami na aprendizagem da matemática. Além disso, os alunos comentaram que a instrução baseada em origami ajudou a desenvolver suas habilidades psicomotoras; melhorando sua imaginação, criatividade e inteligência. Resultados similares foram encontrados por Tugrul; kavici, (2002) e Cakmak et al. (2014). origami no ensino de ciências.

Ao criar modelos por meio dos origamis, os alunos terão a oportunidade de melhorar seu aprendizado. Conforme expresso por Gardner, sobre a aprendizagem e a inteligência visual espacial.

"Tendem a aprender conceitos mais facilmente quando eles são permitidos a mostrar sua compreensão através da arte ou pintura. Os estudantes visualizam imagens claras quando se trata de resolver problemas e pensar em relação aos conceitos" (ANTUNES, 2012, p. 40). 
Reafirmamos a importância de aprender a realizar diferentes modelos que caracterizam a arte em dobrar papel, porque, por meio desta técnica os alunos aprenderão vivenciando, criando, por meio da orientação verbal ou não verbal do professor para realizar diferentes dobraduras, fortalecendo e incrementando $o$ aprendizado em ciências.

Assim, podemos considerar que a aplicação de origami se mostrou relevante para a abstração e compreensão de novos processos. Talvez pelo origami ter uma estrutura tridimensional e apresentar uma linguagem lúdica ele possa facilitar a compreensão de diferentes conceitos. Pope e Lam (2011) observaram que o origami era uma boa maneira de enriquecer o currículo escolar, fornecendo oportunidades para a resolução de problemas e criatividade. Desta forma, o trabalho pode permitir o desenvolvimento das capacidades cognitivas, o conhecimento de uma nova arte e o crescimento a nível técnico e expressivo na formação inicial de professores.

Alinhados com a literatura, os resultados sugerem que o origami poderia ser uma fonte adicional de instrução para aprimorar o Ensino de Ciências. Origami não é apenas uma técnica usada para diversão, mas também pode ser um contexto significativo para o pensamento de alto nível em ciências. No entanto, faz-se necessárias mais pesquisas com variações na estrutura do projeto para determinar como a prática de origami podem ser comparadas a outros métodos de instrumentalização no ensino.

\section{Conclusões}

Verificou-se que o ensino baseado na arte de dobrar papel tem potencial para ser usado como uma ferramenta de aprendizado nas aulas de ciências para melhorar as habilidades dos alunos. Em virtude de suas interações, os estudantes e futuros professores de ciências podem se beneficiar das técnicas de origami para desenvolver suas habilidades.

O uso do origami como meio para a aprendizagem no ensino de ciências produziu resultados positivos que foram comprovados pela contentamento e motivação dos alunos. Tais resultados refletiram em diferentes trabalhos dos estudantes abordando diversos temas. O uso desta arte motivou os discentes a desenvolverem intervenções didáticas mais interativas.

Com relação a pesquisa futura, estudos semelhantes poderiam ser conduzidos em níveis e contextos diferentes para entender melhor os efeitos do ensino baseado em origami no ensino de ciências.

\section{Agradecimentos e apoios}

Agradecemos a todos os alunos da disciplina de verão, Didática de Ciências Naturais da Universidade de Brasília. 


\section{Referências}

AGUIAR, M. A. Políticas de currículo e formação dos profissionais da educação básica no Brasil: desafios para a gestão educacional. Revista Espaço do Currículo, v. 10, n. 1, 2017.

ANTUNES, C. Juegos para estimular las inteligencias múltiples. Bogotá: Narce, S.A, 2012.

AXT, R.; MOREIRA, M. A. O ensino experimental e a questão do equipamento de baixo custo. Revista de Ensino de Física, v. 13, p. 97-103, 1991.

BOAKES, N. J. Origami instruction in the middle school mathematics classroom: Its impact on spatial visualization and geometry knowledge of students. Research in Middle Level Education, v.32, n.7, p.1-12, 2009.

BRASIL. Ministério da Educação e Cultura. Parâmetros Curriculares Nacionais: terceiro e quarto ciclos do Ensino Fundamental-Língua Portuguesa. Brasília: MEC/SEF (1998)..

BRASIL. Ministério da Educação e Cultura. Parâmetros curriculares nacionais: Ensino Médio. Volume 2: Ciências da Natureza, Matemática e Tecnologia. Brasília: MEC, 2006.

CAKMAK, S; ISIKSAL, M; KOC, Y. Investigating effect of origami-based instruction on elementary students' spatial skills and perceptions. The Journal of Educational Research, v. 107, n. 1, p. 59-68, 2014.

CAKMAK, S. An investigation of the effect of origami-based instruction on elementary students' spatial ability in mathematics (Master's thesis). Middle East Technical University, Ankara, Turkey, 2009.

CORRALES, G. M.; SIERRA, M, I. Diseño de Medios y Recursos Didácticos. Málaga: INNOVA, 2002.

FOUREZ, G. Crise no ensino de ciências? Investigações em ensino de ciências, v. 8, n. 2, p. 109-123, 2003.

FREITAS, B. A. Os problemas clássicos da geometria: uma abordagem com o uso do Origami. 2013. 47f. Dissertação (Mestrado). -Universidade Federal do Rio de Janeiro. Rio de Janeiro - 2013.

GOLAN, M. Origametria and the van Hiele theory of teaching geometry. In P. Wang Iverson, R. J. Lang \& M. Yim (Eds.), Origami 5: Fifth international meeting of origami science, mathematics and education (5OSME), 2011. pp. 141-150. Boca Raton: CRC Press.

GARCIA-GUTIERREZ, J. G. Como Hacer Figuras de Papel. Madrid, España: AKAL, 1991.

HOWARD, G. Multiple Intelligences: The Theory in Practice. New York: Skylight Training and Publishing or (www. institute4learning. com/multipleintelligences...), 304p. 1993. 
JUSTINA, L. A. D.; FERLA, M. R. A utilização de modelos didáticos no ensino de genética - exemplo de representação de compactação do DNA eucarioto. Arq Mudi.Maringá/PR, 2006.

KARLING, A. A. A. Didática Necessária (The Required Didactic). São Paulo, SP: IBRASA, 1991.

MARQUES, P. M. M. A criatividade como competência essencial no desenvolvimento progressivo do aluno em artes visuais. 2016. 130f. Tese de Doutorado. Universidade de Lisboa, Lisboa. 2016.

MEGAHED, N. A. Origami Folding and its Potential for Architecture Students. The Design Journal, v. 20, n. 2, p. 279-297, 2017.

PIAGET, J. Seis estudos de psicologia. Trad. Maria Alice Magalhães D'Amorim e Paulo Sergio Lima Silva. 21. ed., Rio de Janeiro: Forense Universitária, 1995.

POPE, S., LAM, T. K. Origami and learning mathematics. In P. Wang Iverson, R. J. Lang \& M. Yim (Eds.), Origami 5: Fifth international meeting of origami science, mathematics and education (5OSME), 2011. p. 205-218. Boca Raton: CRC Press

RANCAN, G. Origami e Tecnologia: Investigando Possibilidades para Ensinar Geometria no Ensino Fundamental. Porto Alegre, 2011. 80 f. Dissertação (Mestrado em Educação em Ciência e Matemática) Faculdade de Física, PUCRS.

SETÚVAL, F. A. R.; BEJARANO, N. R. R. Os modelos didáticos com conteúdos de Genética e a sua importância na formação inicial de professores para o ensino de ciências e biologia. VII Encontro Nacional de Pesquisa em Educação em Ciências. Florianópolis, 2009.

TÉLLEZ, M. N. B.; DÍAZ, M. C.; GÓMEZ, A. R. Piaget y LS Vigotsky en el análisis de la relación entre educación y desarrollo. Revista Iberoamericana de Educación, v. 42, p. 7-25, 2007.

TREAGUST, D.; TSUI, C. Y. Commentary: Developments and Reforms in Science Education for Improving the Quality of Teaching and Research. In: Science Education Research and Practice in Asia. Springer Singapore, p. 119-128, 2016.

TUGRUL, B.; KAVICI, M. Kagit katlama sanati ve ogrenme [The art of paper folding and learning]. Pamukkale University Education Faculty Journal, v. 11, n. 11, p. 1-17, 2002.

WINCKLER, M. J.; WOLF, K. D.; BOCK, H. G. Hands-on geometry with origami. In P. WANG-IVERSON, P.; LANG, R. J; MARK, Y (Eds.), Origami 5: Fifth international meeting of origami science, mathematics and education (5OSME), 2016. pp. 219-232. Boca Raton: CRC Press.

Submissão: 15/05/2017

Aceite: $13 / 05 / 2018$ 